TITLE:

\title{
Quench Experiments of Conduction-Cooled Coated Conductors with Various Copper- Stabilizer Thicknesses
}

\section{$\operatorname{AUTHOR}(S):$}

Luo, Xijie; Inoue, Satoru; Amemiya, Naoyuki

\section{CITATION:}

Luo, Xijie ...[et al]. Quench Experiments of Conduction-Cooled Coated Conductors with Various Copper-Stabilizer Thicknesses. IEEE Transactions on Applied Superconductivity 2020, 30(4): 8936872.

\section{ISSUE DATE:}

2020-06

URL:

http://hdl.handle.net/2433/245869

\section{RIGHT:}

(C) 2020 IEEE. Personal use of this material is permitted. Permission from IEEE must be obtained for all other uses, in any current or future media, including reprinting/republishing this material for advertising or promotional purposes, creating new collective works, for resale or redistribution to servers or lists, or reuse of any copyrighted component of this work in other works.; The full-text file will be made open to the public on 19 December 2021 in accordance with publisher's 'Terms and Conditions for Self-Archiving'. This is not the published version. Please cite only the published version.; この論文は出版社版でありません。引用の際には出版社版をご確認ざ利用ください。 


\title{
Quench Experiments of Conduction-Cooled Coated Conductors with Various Copper-Stabilizer Thick-
} nesses

\author{
Xijie Luo, Satoru Inoue, and Naoyuki Amemiya, Member, IEEE
}

\begin{abstract}
We experimentally studied the quench properties of $\mathrm{REBa}_{2} \mathrm{Cu}_{3} \mathrm{O}_{\mathrm{y}}$ (RE-123) coated conductors with various platedcopper thicknesses $(20$ and $40 \mu \mathrm{m})$. A short sample of coated conductors was conduction-cooled to $45 \mathrm{~K}$, a magnetic field $\left(\mu_{0} \mathrm{H}\right.$, up to $2 \mathrm{~T}$ ) was applied perpendicular to its wide face to control the critical current, an operating current was supplied, and subsequently quench was initiated using a small heater. Normal zone propagation velocities (NZPVs) were measured at various operating currents, and the NZPVs of coated conductors with various copper thicknesses were compared with each other. To understand the impact of the copper stabilizer on quench protection, hot-spot temperatures were measured during the processes that simulate quench detection using voltage taps and protection using dump resistor. The maximum hot-spot temperatures were plotted against the operating current as well as the overall current density, and the impact of the thickness of the copper stabilizer on hot-spot temperature was examined. The impact of the initial temperature on hot-spot temperature was also studied.
\end{abstract}

Index Terms-Coated conductor, conduction-cooled, copper stabilizer, protection, quench.

\section{INTRODUCTION}

$\mathbf{T}$ HE amount of copper stabilizer in the cross section of a superconductor is a significant parameter in the context of quench protection because it directly impacts the Joule heating in the quench process [1]. In the early stage of the development of $\mathrm{REBa}_{2} \mathrm{Cu}_{3} \mathrm{O}_{\mathrm{y}}$ (RE-123) coated conductors, their superconductor layers were covered only with several-micrometerthick silver layers [2]. Recently, attaching copper stabilizer has become common in commercially available coated conductors, but their cross sections are still relatively small [3]-[4]. For example, in the case of a 4-mm-wide coated conductor plated with $20-\mu \mathrm{m}$-thick copper carrying $200 \mathrm{~A}$ of current, its copper current density in the event of quench is $1250 \mathrm{~A} / \mathrm{mm}^{2}$.

Manuscript receipt and acceptance dates will be inserted here. This work was supported in part by the Japan Science and Technology Agency under the Strategic Promotion of Innovative Research and Development Program (SInnovation Program) Grant Number JPMJSV0919, the JSPS Grants-in-Aid for Scientific Research Grant Number JP18KK0087, and Japan-U.S. Science and Technology Cooperation Program in High Energy Physics. (Corresponding author: Naoyuki Amemiya.)

Xijie Luo, Satoru Inoue, and Naoyuki Amemiya are with the Department of Electrical Engineering, Kyoto University, Kyoto 615-8510, Japan (e-mail: amemiya.naoyuki.6a@kyoto-u.ac.jp).

Color versions of one or more of the figures in this paper are available online at http://ieeexplore.iee.org.

Digital Object Identifier will be inserted here upon acceptance.
Several studies have been conducted on the normal zone propagation velocity (NZPV), focusing on the copper stabilizer in coated conductors numerically [5] and experimentally (at $77 \mathrm{~K}$ ) [6]. In this study, we particularly measured the NZPV of conduction-cooled coated conductors with platedcopper stabilizers of various thicknesses.

To understand the impact of copper stabilizer on quench protection, we performed quench detection and protection experiments at various operating currents using the conventional quench detection and protection scheme, i.e., detecting quench using voltage and dumping the stored energy in an external dump resistor, because of the simplicity and well-established hardware for a real magnet.

\section{EXPERIMENTAL METHOD}

The specifications of the samples used in this study are listed in Table I. The thicknesses of the Hastelloy substrates in FYSC-SCH04 and FYSC-SCH04(40) are the same, but the copper stabilizer in FYSC-SCH04(40) is thicker. The platedcopper thicknesses of FYSC-SCH04 and SCS4050 are the same, but the Hastelloy substrate in FYSC-CSH04 is thicker. The critical currents of the samples were measured at various temperatures and are depicted in Fig. 1. The positions of the voltage taps and temperature sensors are depicted in Fig. 2. The entire length of a sample, including the length attached to the copper current terminals ( $25 \mathrm{~mm}$ each), was $230 \mathrm{~mm}$. The temperature of the sample was PID-controlled at $45 \mathrm{~K}$ (in most experiments) using the temperature measured by CX1 and CX2 as well as heaters (not shown in Fig. 2) near the copper terminals. One side of sample faces vacuum and the other side is attached to a GFRP sample holder through epoxy resin and polyimide tape.

In this study, hot-spot temperature during the quench process was calculated from $v_{5-6}$ based on the current sharing model and the temperature dependence of the resistivity of plated copper, which was introduced in a previous study [7].

Fig. 3(a) depicts the voltage and current waveforms in an example of NZPV measurement. We used the time when $v_{4-5}$ (voltage between VT4 and VT5) and $v_{3-4}$ (voltage between VT3 and VT4) reach $1 \mathrm{mV}$ as well as $d_{4-5}$ (distance between VT4 and VT5: $15 \mathrm{~mm}$ ) to estimate the NZPV. Fig. 3(b) depicts the typical data of quench detection and protection shot. 
TABLE I

SPECIFICATIONS OF SAMPLE

\begin{tabular}{llll}
\hline \hline \multicolumn{1}{c}{ Properties } & $\begin{array}{c}\text { FYSC- } \\
\text { SCH04 } \\
\text { (Fujikura) }\end{array}$ & $\begin{array}{c}\text { FYSC- } \\
\text { SCH04(40) } \\
\text { (Fujikura) }\end{array}$ & $\begin{array}{c}\text { SCS4050 } \\
\text { (SuperPower) }\end{array}$ \\
\hline Width & $4 \mathrm{~mm}$ & $4 \mathrm{~mm}$ & $4 \mathrm{~mm}$ \\
Entire thickness & $0.13 \mathrm{~mm}$ & $0.17 \mathrm{~mm}$ & $0.1 \mathrm{~mm}$ \\
Plated-copper thickness & $20 \mu \mathrm{m}$ & $40 \mu \mathrm{m}$ & $20 \mu \mathrm{m}$ \\
$\begin{array}{l}\text { Thickness of Hastelloy } \\
\text { substrate }\end{array}$ & $75 \mu \mathrm{m}$ & $75 \mu \mathrm{m}$ & $50 \mu \mathrm{m}$ \\
Critical current & $\sim 320 \mathrm{~A}$ & $\sim 320 \mathrm{~A}$ & $\sim 320 \mathrm{~A}$ \\
& $(45 \mathrm{~K}, 2 \mathrm{~T})$ & $(45 \mathrm{~K}, 2 \mathrm{~T})$ & $(45 \mathrm{~K}, 0.4 \mathrm{~T})$ \\
\hline \hline
\end{tabular}

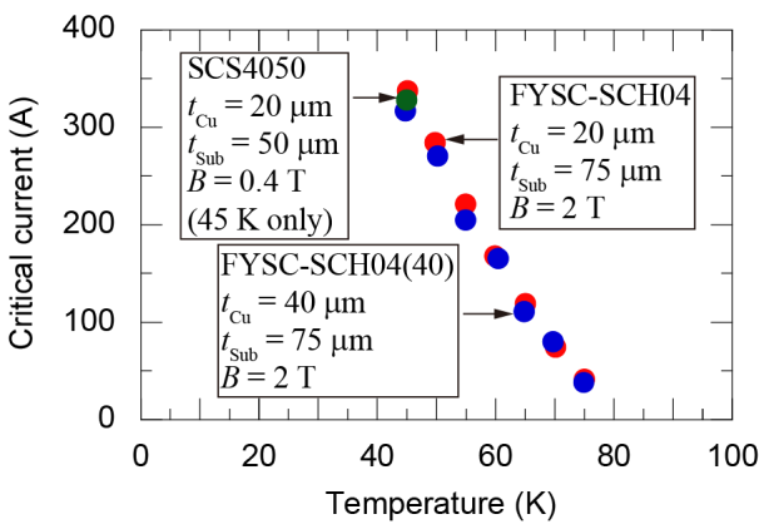

Fig. 1. Critical current of samples measured at various temperatures $\left(E_{0}=100 \mu \mathrm{V} / \mathrm{m}\right)$

A field-programmable gate array (FPGA) was used to monitor the voltage and control the output of power supply. Once the monitored voltage of the entire sample $\left(v_{1-10}\right)$ reached a detection voltage (simulating quench detection), after a period of delay (simulating the time required for detection in a real coil and for activating the circuit breaker), the sample current was decreased exponentially (simulating current decay by the dump resistor while neglecting the normal resistance). The critical currents and $n$ values of a sample before and after quench are used to determine whether there is degradation or not. In all the quench detection and protection experiments in this study, the threshold voltage was set to $100 \mathrm{mV}$ and the delay time was set to $100 \mathrm{~ms}$.

\section{EXPERIMENTAL RESULTS AND DISCUSSION}

\section{A. Normal Zone Propagation Velocity}

The NZPVs of coated conductors with various platedcopper thicknesses (FYSC-SCH04, FYSC-SCH04(40)) at various operating currents were measured at $45 \mathrm{~K}, 2 \mathrm{~T}$, as depicted in Fig. 4. Ignoring the transverse thermal diffusion, the NZPV could be calculated using the following equation [8]:

$$
v=\frac{J}{\gamma C}\left\{\frac{L_{0}\left(T_{\mathrm{g}}+T_{\mathrm{c}}\right)}{T_{\mathrm{g}}+T_{\mathrm{c}}-2 T_{0}}\right\}^{\frac{1}{2}}
$$

where $J$ represents the overall current density, $L_{0}$ is the Lorentz number $\left(2.45 \times 10^{-8} \mathrm{~W} \cdot \Omega \cdot \mathrm{K}^{-2}\right)$ from the WiedemannFranz-Lorentz law, $T_{\mathrm{g}}$ is the temperature at which heat is generated, $T_{\mathrm{c}}$ is the critical temperature (assumed as $82 \mathrm{~K}$, based

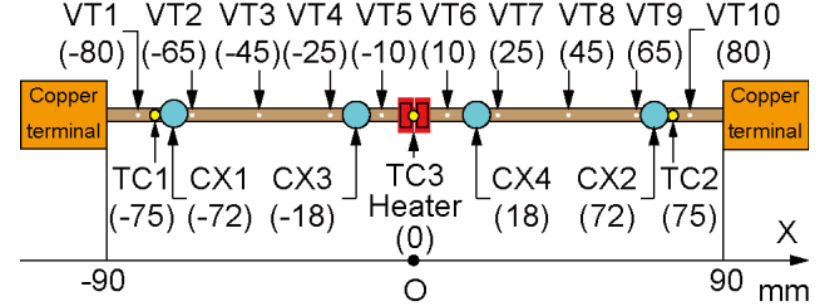

Fig. 2. Positions of voltage taps and temperature sensors (VT: voltage tap, TC: thermocouple, CX: Cernox temperature sensor). Numbers in brackets indicate relative positions (in $\mathrm{mm}$ ) to sample center in longitude direction.

(a)
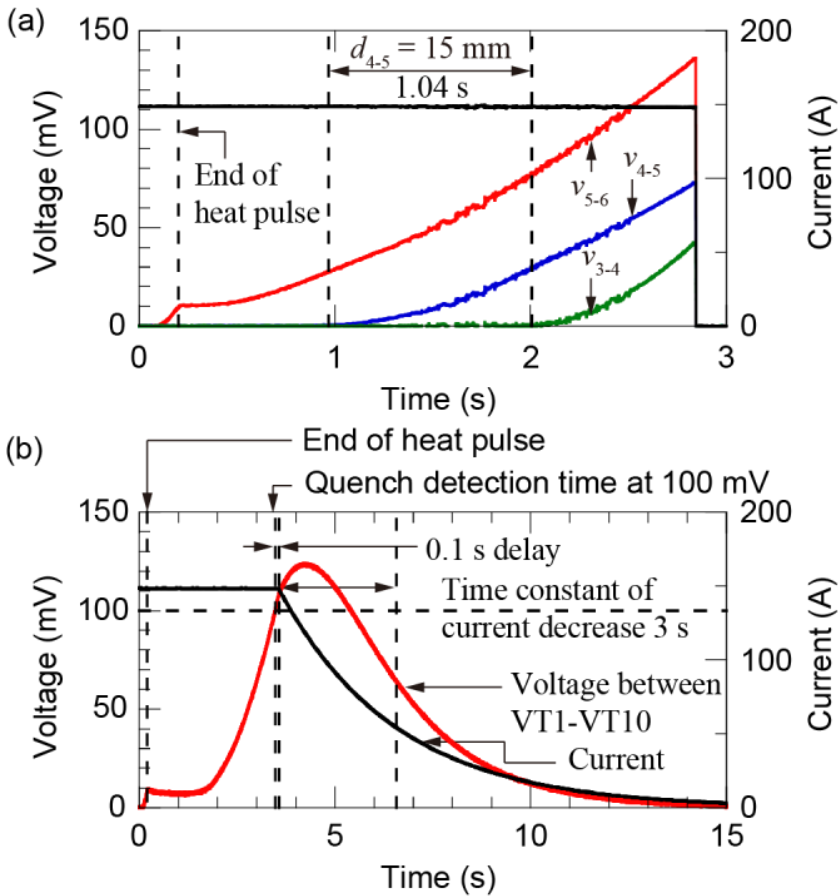

Fig. 3. The example of NZPV measurement, quench detection, and protection experiment $\left(T_{\mathrm{i}}=45 \mathrm{~K}, B=2 \mathrm{~T}, I_{\mathrm{op}}=150 \mathrm{~A}\right.$, FYSC-SCH04(40), $v_{m-n}$ : voltage between $\mathrm{VT} m$ and $\mathrm{VT} n, d_{m-n}$ : distance between VT $m$ and $\mathrm{VT} n$ ): (a) voltage and current in NZPV measurement, (b) voltage and current in quench detection and protection experiment.

on the measured data in Fig. 1), and $T_{0}$ is the initial temperature $(45 \mathrm{~K})$. The parameter $T_{\mathrm{g}}$ is expressed as follows:

$$
T_{\mathrm{g}}=T_{\mathrm{c}}-\left(T_{\mathrm{c}}-T_{0}\right) \frac{J}{J_{\mathrm{c} 0}}
$$

where $J_{\mathrm{c} 0}$ is the overall critical current density at the initial temperature $\left(672 \mathrm{~A} / \mathrm{mm}^{2}\right.$ in FYSC-SCH04 and $503 \mathrm{~A} / \mathrm{mm}^{2}$ in FYSC-SCH04(40)). The heat capacity $\gamma C$ is calculated by considering the mean over the temperature range of the transition.

$$
\gamma=\left\{\frac{T_{\mathrm{c}}^{4}-T_{0}^{4}}{4 T_{0}^{3}\left(T_{\mathrm{c}}-T_{0}\right)}\right\} \sum_{n} \lambda_{n} \gamma_{n} C_{0 n}
$$

where $\lambda_{n}$ is the proportion of the $n$th component, $\gamma_{n}$ is its density, $C_{0 n}$ is its specific heat at $T_{0}$, and it is assumed that $C$ varies as $T^{3} \cdot \gamma C=1.84 \times 10^{6} \mathrm{~J} / \mathrm{m}^{3} \cdot \mathrm{K}$ in FYSC-SCH04 and $\gamma C=$ $1.86 \times 10^{6} \mathrm{~J} / \mathrm{m}^{3} \cdot \mathrm{K}$ in FYSC-SCH04(40). The calculated NZPVs are represented as dashed lines in Fig. 4. The measured NZPVs were lower as compared to the calculated results, which might be attributed to transverse thermal diffusion in 


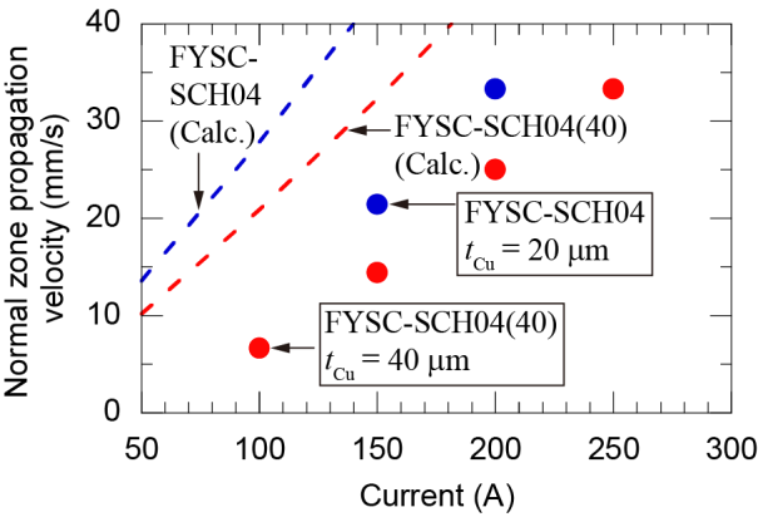

Fig. 4. NZPV vs current in coated conductors with different copper thicknesses $\left(T_{\mathrm{i}}=45 \mathrm{~K}, B=2 \mathrm{~T}, I_{c} \sim 320 \mathrm{~A}\right)$.

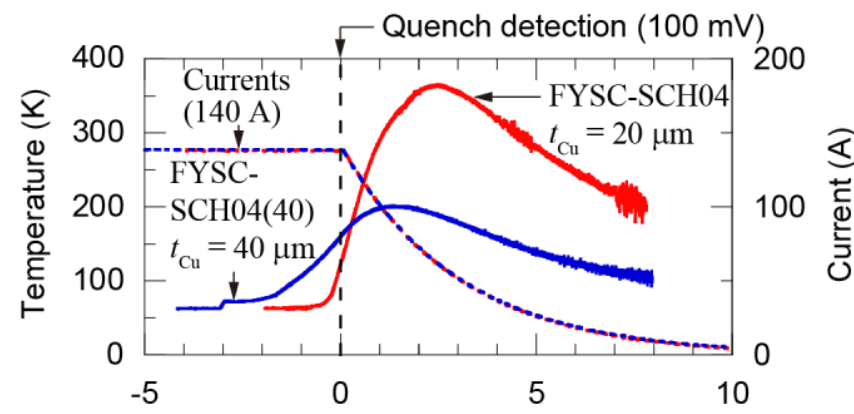

Time from quench detection (s)

Fig. 5. Hot-spot temperature and current waveforms of samples with different copper thicknesses $\left(T_{\mathrm{i}}=45 \mathrm{~K}, B=2 \mathrm{~T}, I_{c} \sim 320 \mathrm{~A}, I_{\mathrm{op}}=140 \mathrm{~A}, v_{\mathrm{th}}=\right.$ $100 \mathrm{mV}, t_{\mathrm{d}}=100 \mathrm{~ms}, \tau=3 \mathrm{~s}$ )

the experiments. Also some assuming on physical properties ( $C$ varies as $T^{3}$, ignoring the effect of magnetic field) might have some influences on such differences between calculated and measured results. Both the calculated and experimental results indicate that increasing the thickness of plated copper in a coated conductor causes a decrease in the propagation velocity. In previous study, it was reported that the increasing of heat capacity is the main reason for the decrease in NZPV when increasing copper thickness [6]. However, based on (1), as these two samples have nearly the same values of $T_{\mathrm{g}}, T_{\mathrm{c}}$, and $T_{0}$, and there is not too much of difference in the heat capacity $\gamma C$ between these two coated conductors, it is considered that the decrease in the overall current density $J$ (by increasing the thickness of the copper stabilizer) is the main reason for this decrease in NZPV.

\section{B. Hot-spot Temperature During Quench Detection and Pro- tection Process}

Fig. 5 illustrates an example of hot-spot temperature and current waveforms during the quench detection and protection process using samples with various copper thicknesses. The figure suggests that increasing the copper thickness decreases the maximum hot-spot temperature during the quench detection and protection process. Such experiments were conducted with various operating currents and time constants. As depicted in Fig. 6(a), at first, the experiments were performed using FYSC-SCH04 and FYSC-SCH04(40), setting the time constant of current decrease as $1 \mathrm{~s}$, and the current at the first shot was $100 \mathrm{~A}$ and was raised incrementally. It is clear that at the same operating current, the maximum hot-spot temperature (a)

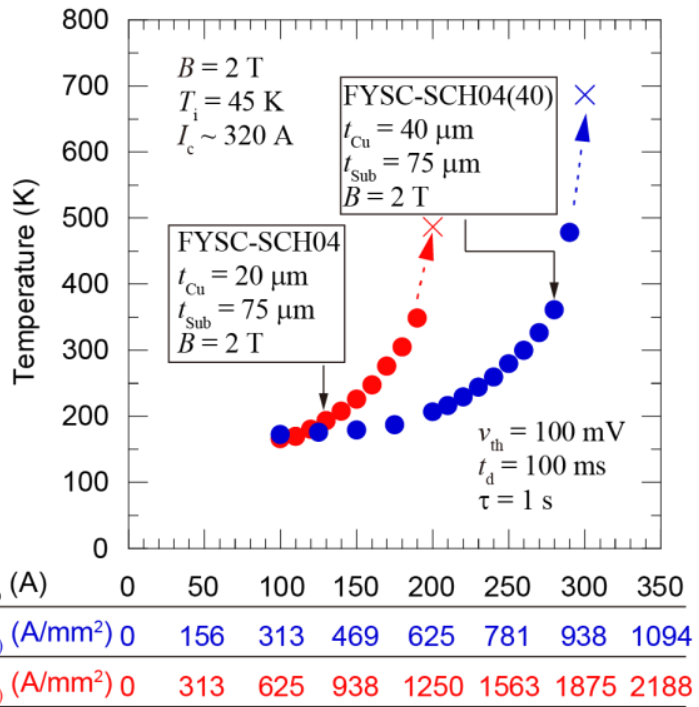

(b)

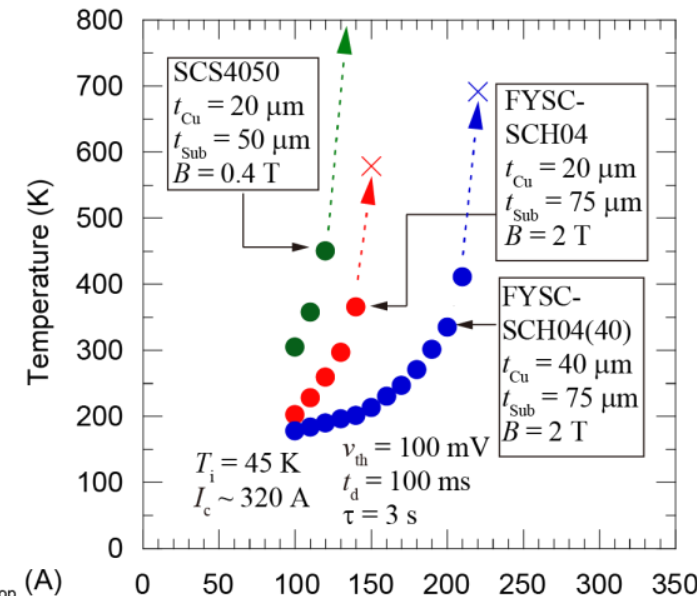

\begin{tabular}{llllllll}
\hline$J_{\mathrm{Cu}(40 \mu \mathrm{m})}\left(\mathrm{A} / \mathrm{mm}^{2}\right) 0$ & 156 & 313 & 469 & 625 & 781 & 938 & 1094
\end{tabular}

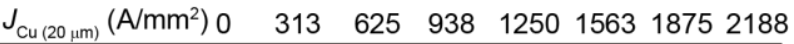

Fig. 6. Maximum hot-spot temperature vs operating current/current density $\left(T_{\mathrm{i}}=45 \mathrm{~K}, t_{\mathrm{d}}=100 \mathrm{~ms}\right.$ ): (a) $\tau=1 \mathrm{~s}$; (b) $\tau=3 \mathrm{~s}$.

was lower in FYSC-SCH04(40). For example, at $150 \mathrm{~A}$, the maximum hot-spot temperature in FYSC-SCH04 was $225 \mathrm{~K}$ $\left(J_{\mathrm{Cu}}=938 \mathrm{~A} / \mathrm{mm}^{2}\right)$, whereas the maximum hot-spot temperature in FYSC-SCH04(40) was $179 \mathrm{~K}\left(J_{\mathrm{Cu}}=469 \mathrm{~A} / \mathrm{mm}^{2}\right)$. As depicted in Fig. 6(b), similar experiments were conducted when the time constant was set to $3 \mathrm{~s}$ using FYSC-SCH04, FYSC-SCH04(40), and SCS4050. It should be noted that in the experiments using SCS4050, the magnetic field was set to $0.4 \mathrm{~T}$ to let the critical current be close to the other two types of coated conductors. In both Fig. 6(a) and Fig. 6(b), the experimental results of FYSC-SCH04 and FYSC-SCH04(40) demonstrated the impact of increasing the copper thickness on decreasing the maximum hot-spot temperature owing to the decrease in copper current density as well as the increase in the heat capacity. Further, the experimental results of FYSCSCH04 and SCS4050 suggest that increasing the Hastelloy substrate thickness impacts the maximum hot-spot temperature remarkably (e.g., it was $202 \mathrm{~K}$ in FYSC-SCH04 but $305 \mathrm{~K}$ in SCS4050 at $100 \mathrm{~A}$ ) owing to the increase in the heat capacity. 
(a)

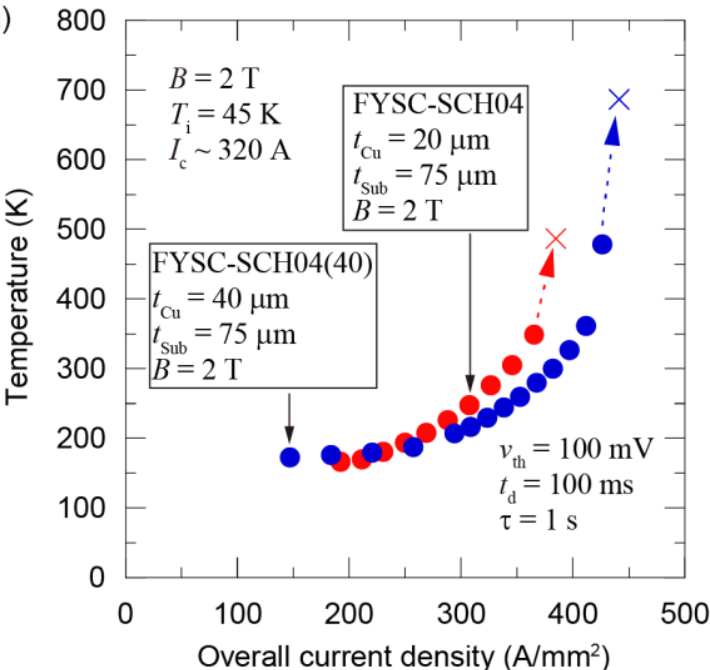

(b)

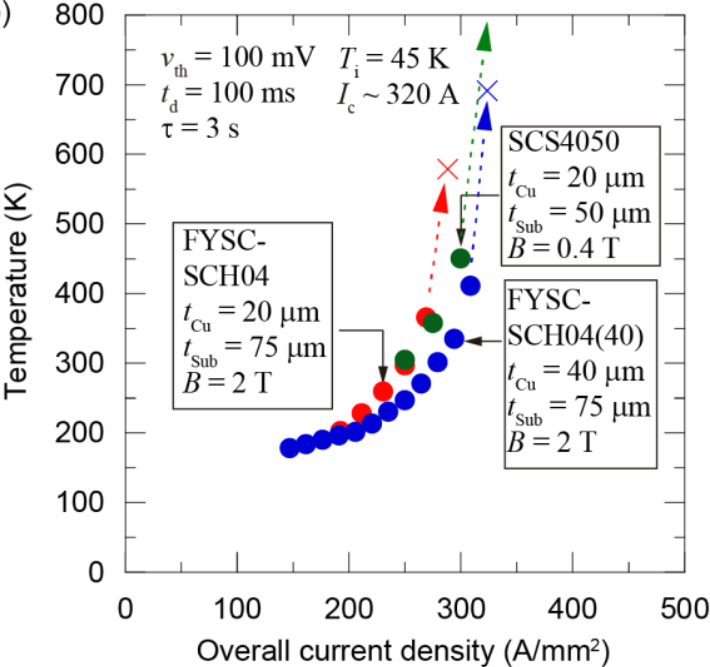

Fig. 7. Maximum hot-spot temperature vs copper current density $\left(T_{\mathrm{i}}=45\right.$ $\mathrm{K}, t_{\mathrm{d}}=100 \mathrm{~ms}$ ): (a) $\tau=1 \mathrm{~s}$, (b) $\tau=3 \mathrm{~s}$

Fig. 6 depicts that increasing the copper thickness of a coated conductor reduces the copper current density and the maximum hot-spot temperature. However, increasing the copper thickness of a coated conductor could also reduce the overall current density, which is required to be high in a real magnet. To understand whether it is beneficial to increase the copper thickness, considering the overall current density, we compared the maximum hot-spot temperature at various overall current densities using various samples, as depicted in Fig. 7. The experimental results for FYSC-SCH04 and FYSCSCH04(40), depicted in Fig. 7, suggest that at the same overall current density, the hotspot temperature of a coated conductor with a thicker copper stabilizer $(40 \mu \mathrm{m})$ could be rather lower. However, as depicted in Fig. 7(b), the results of FYSC-SCH04 and SCS4050 suggest that the relation between the hot-spot temperature and overall current density does not change substantially by changing the thickness of the Hastelloy substrate.

\section{Impact of Initial Temperatures}

Fig. 8 displays the waveforms of the hot-spot temperature and current of FYSC-SCH04(40) when the initial temperature was varied. The experiments were performed at $150 \mathrm{~A}$ with

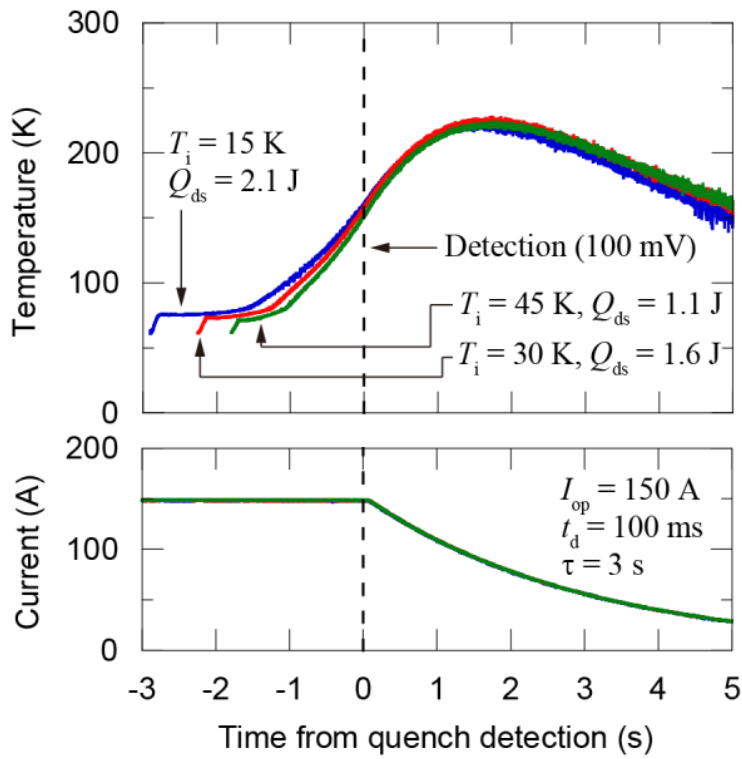

Fig. 8. Hot spot temperature and current at various initial temperatures (FYSC-SCH04(40), $I_{\mathrm{op}}=150 \mathrm{~A}, v_{\mathrm{th}}=100 \mathrm{mV}, t_{\mathrm{d}}=100 \mathrm{~ms}, \tau=3 \mathrm{~s}$ ).

the same time constant of current decrease ( $3 \mathrm{~s})$. No significant difference was observed among the hot-spot temperatures after quench detection, which suggests that the initial temperature has little impact on quench detection and protection.

In Fig. 8, the energies of thermal disturbance causing quench were $2.1 \mathrm{~J}$ at $15 \mathrm{~K}, 1.6 \mathrm{~J}$ at $30 \mathrm{~K}$, and $1.1 \mathrm{~J}$ at $45 \mathrm{~K}$. Ignoring thermal conduction, the enthalpy margin can be calculated at various temperatures using the following equation [9]:

$$
H\left(T_{0}\right)=\int_{T_{0}}^{T_{\mathrm{i}}} \gamma C(T) d T
$$

where $T_{\mathrm{i}}$ is the temperature at which the electric field reaches $100 \mu \mathrm{V} / \mathrm{m}$, which is $62 \mathrm{~K}$ in this case, and $\gamma C(T)$ is the volumetric specific heat of the conductor averaged over its cross section. The calculated enthalpy margins are as follows: $2.3 \times$ $10^{7} \mathrm{~J} / \mathrm{m}^{3}$ at $15 \mathrm{~K}, 2.1 \times 10^{7} \mathrm{~J} / \mathrm{m}^{3}$ at $30 \mathrm{~K}$, and $1.5 \times 10^{7} \mathrm{~J} / \mathrm{m}^{3}$ at $45 \mathrm{~K}$. The energies of thermal disturbance causing quench in the experiments as well as the enthalpy margin suggest that the initial temperature does not considerably impact the energy that induces a quench at low temperature.

\section{SUMMARY}

Using conduction-cooled coated conductors, we experimentally confirmed that increasing the thickness of plated copper decreases the propagation velocity and suppresses hot-spot temperature. Decreasing the overall current density could cause the former and decreasing the copper current density could cause the latter. The heat capacity of the substrate has a remarkable impact on the hot-spot temperature. Essentially, the hot-spot temperatures of the coated conductor with $40-\mu \mathrm{m}$ thick plated copper were lower than those of the coated conductor with $20-\mu \mathrm{m}$-thick plated copper at the same overall current densities. The initial temperature hardly impacts the hotspot temperature. 


\section{REFERENCES}

[1] Y. Fu, O. Tsukamoto, and M. Furuse, "Copper stabilization of YBCO coated conductor for quench protection," IEEE Trans. Appl. Supercond., vol. 13, no. 2, pp. 1780-1783, Jun. 2003.

[2] A. P. Malozemoff, S. Annavarapu, L. Fritzemeier, Q. Li, V. Prunier, M. Rupich, C. Thieme, W. Zhang, A. Goyal, M. Paranthaman, and D. F. Lee, "Low-cost YBCO coated conductor technology," Supercond. Sci. Technol., vol. 13, no. 5, pp. 473-476, May 2000.

[3] A. P. Malozemoff, S. Fleshler, M. Rumpich, C. Thieme, X. Li, W. Zhang, A. Otto, J. Maguire, D. Folts, J. Yuan, H-P. Kraemer, W. Schmidt, M. Wohlfart, and H- W. Neumueller, "Progress in high temperature superconductor coated conductors and their applications," Supercond. Sci. Technol., vol. 21, no. 3, Mar. 2008, Art. no. 034005.

[4] M. W. Rupich, X. Li, S. Sathyamurthy, C. L. H. Thieme, K. DeMoranville, J. Gannon, and S. Fleshler, "Second generation wire development at AMSC," IEEE Trans. Appl. Supercond., vol. 23, no. 3, Jun. 2013, Art. no. 6601205 .

[5] C. Lacroix, F. Sirois, and J-H. F. Lupien, "Engineering of second generation HTS coated conductor architecture to enhance the normal zone propagation velocity in various operating conditions," Supercond. Sci. Technol., vol. 30, no. 6, Jun. 2017, Art no. 064004.

[6] M. Daibo, S. Fujita, M. Haraguchi, Y. Iijima, and T. Saitoh, "Evaluation of the normal-zone propagation characteristics of REBCO coated conductors with laminated Cu tape," IEEE Trans. Appl. Supercond., vol. 21, no. 3, pp. 2428-2431, Jun. 2011.

[7] X. Luo, S. Inoue, N. Amemiya, "Experimental study on quench detection and protection conditions of copper-stabilized coated conductors using short samples," IEEE Trans. Appl. Supercond., vol. 29, no. 8, Dec. 2019, Art. no. 4703511.

[8] M. N. Wilson, "Propagation velocities," in Superconducting Magnets, Oxford, U.K.: Clarendon, 1983, pp. 204-208.

[9] K. Takahashi, N. Amemiya, T. Nakamura, T. Ogitsu, T. Kurusu, T. Yoshiyuki, K. Noda, and S. Awaji, "Magnetic field design of dipole magnet wound with coated conductor considering its current transport characteristics," IEEE Trans. Appl. Supercond., vol. 21, no. 3, pp. 1833-1837, Jun. 2011. 